\title{
Los andamios de la estética en el periodismo. En los umbrales de la práctica
}

\section{The scaffoldings of aesthetics in journalism. On the thresholds of practice}

Recibido: 20/11/2020

Aceptado: 01/06/2021

Publicado: 30/06/2021
Flor de Liz Pérez Morales

flor.perez@ujat.mx https://orcid.org/0000-0001-6478-3727

Universidad Juárez Autónoma de Tabasco (México)

Resumen: El trabajo que aquí se presenta inquiere en la noción del arco estético que mina el proceso periodístico; esto refiere a la construcción de una punta de lanza teórico-metodológica que focaliza la intención de la estética como recurso transversal en el proceso periodístico. El periodismo y la vida cotidiana es una relación que explica el vínculo de sus transformaciones mutuas, lo que significa que la práctica periodística debe estar en constante interrogatorio. De aquí emerge el supuesto general: en todo proceso periodístico permea un elemento sensitivo que bajo la incidencia del estatuto estético recorre una ruta, determinada por el acontecimiento. La investigación se inscribe como un proceso cualitativo exploratorio, sobre una perspectiva sociocultural. De la experiencia enunciada se presenta una cartografía teórica metodológica, que al amparo de la hermenéutica y la teoría fundamentada da cuenta de los referentes clave del estudio.

Palabras clave: Acontecimiento, Arco estético, Investigador-escritor, Lector, Proceso periodístico. 
Abstract: The work presented here inquires into the notion of the Aesthetic Arch that flowing the journalistic process; this refers to the construction of a theoretical-methodological spearhead that focuses the intention of aesthetics as a transversal resource in the journalistic process. Journalism and daily life is a relationship that explains the link of their mutual transformations; this means that the journalistic practice must be constantly questioned. From here emerges the general assumption: in every journalistic process permeates a sensitive element that under the influence of the aesthetic status travels a route, determined by the event. The research is inscribed as an exploratory qualitative process, on a socio-cultural perspective. From the aforementioned experience, a methodological theoretical cartography is presented, which under the protection of hermeneutics and grounded theory accounts for the key references of the research.

Key words: Event, Aesthetic arc, Researcher-writer, Reader, Journalistic process.

\section{Introducción}

Algo ha cambiado en el mundo. El siglo XXI muestra los avatares de nuestra realidad, ángulos poliformes que acusan las vivencias de las sociedades de hoy. Tabasco, México y el mundo son activos que muestran estas experiencias en las resonancias del periodismo. Cassany (2008) lo explica con mucha nitidez, "del mismo modo que cambia la forma de cocinar, los autos que manejamos o los vestidos que llevamos, también cambian los textos que utilizamos, según su lugar y el momento en que comamos, viajemos o nos vistamos" (p. 11). Pero no se trata solo de los cambios manifiestos en la escritura o el manejo de la palabra; tales transformaciones además acusan a una praxis social que hoy también plantea sus propias urgencias: el periodismo.

La idea de que el periodismo y la vida cotidiana se implican dialécticamente es una postura que explica el vínculo de sus transformaciones mutuas, esto significa que la práctica periodística debe estar en constante interrogatorio. El estudio del periodismo conlleva la necesaria exploración de un territorio sociocultural altamente dinámico, lo que debe inquietar siempre la búsqueda de miradas renovadoras que hagan repensar su tarea social. 
Kapuscinski (2006) afirmaba que en el periodismo la actualización y el estudio constante son la conditio sine qua non. El autor aseveraba que el trabajo consiste en investigar y describir el mundo contemporáneo, que está en cambio continuo, profundo, dinámico y revolucionario. Estas afirmaciones permitieron abrir el primer supuesto, mismo que condujo a un estudio exploratorio iniciado en 2008. La primera etapa de este enfatizaba en las formas de escritura que se desarrollaban en el periodismo contemporáneo, cuya tesis era: la incursión del relato periodístico corto, sobre la base de la narración y la opinión, posibilita alternativas lectoras para el periodismo.

Sin embargo, el estudio transitó en la búsqueda de referentes y explicaciones analíticas sobre la práctica periodística. Se trataba, entonces, de indagar más en el proceso periodístico, entenderlo en las fibras que lo mueven, comprenderlo en la multiplicidad de sentidos que aloja y con los que se dibuja. Perniola (2008) dice que "todo se esclarece si fijamos la atención en el sentir que ha acompañado las ideas, los proyectos, las creencias y las obras más variadas, brindándoles un aire familiar y marcándolos con un sello único” (p.28). La tarea se orienta, por tanto, en comprender cómo estos sentidos se constituyen en un lenguaje particular, cuya naturaleza se articula con una condición de estesis que necesariamente intima con otros pathos. Mandoki (2006) explica estas fibras estéticas como "la sensibilidad o condición de abertura o permeabilidad del sujeto al contexto en que está inmerso" (p.6). Justo en este punto es donde se ancla un elemento clave que muy poco se ha discutido en periodismo, como es el trasfondo estético.

Kapuscinski (2006) reflexionaba sobre dos rasgos que debían ser parte del periodismo: el estudio de la historia y de la poesía. La historia, porque brinda los referentes de información con los que se formula la explicación de los diversos temas periodísticos; y la poesía, cuya esencia sensibiliza y enriquece el lenguaje con el que trabaja el periodista. Es sobre este último trazo donde se permean los sentidos del investigador-escritor.

Previamente, en la investigación académica que dio como resultado el trabajo denominado De la historia oral al periodismo literario. Una vía de aproximación a la enseñanza del oficio (2004), ya se apuntaban algunas aristas de la dimensión estética a través de la narrativa, donde se hacía énfasis en el asunto de la creación de un texto. Este trabajo continuó con la tesis de investigación de Guillén de Dios, Ética y Estética: el periodismo literario como herramienta para narrar historias de la comunidad transgénero (2018). 
Lo anterior focaliza la mirada en la comprensión de los sentidos que se alojan en un texto periodístico. Hay una frase de Cassany (2008) que vale la pena retomar: "nuestras miradas del mundo dependen de diversas variables, son ellas las que se proyectan en nuestra voz, sea hablada o escrita" (p. 22). Esas variables son las que tonifican la presencia de la estética en el periodismo, es decir, esta explicación alude a una dimensión que no solo puede verse en el arte, sino también en la vida cotidiana, lo que extiende un horizonte más amplio. Aquí emerge el supuesto general que determina el rumbo de la segunda etapa del estudio: en todo proceso periodístico permea un elemento sensitivo que bajo la incidencia del estatuto estético recorre una ruta, determinada por el acontecimiento. Este marcaje hipotético centra el objetivo investigativo en el análisis de la práctica, recuperada desde la experiencia periodística del investigador-escritor.

En el año 2008, dio inicio este trabajo de investigación y escritura periodística, quehacer que tuvo su mejor recurso en la observación y experimentación de estos presupuestos relacionados con la práctica. Más allá de la producción de escritos periodísticos que fueron publicados en su momento en diversos medios periodísticos impresos y digitales, el objetivo central estaba en reflexionar sobre recursos periodísticos cuya experiencia pudiera surcar el territorio de lo académico. De ahí que surgieron tres obras donde se planteaban algunas reflexiones sobre periodismo: Al encuentro del oficio periodístico (2008), donde se discutía la vocación interdisciplinar y transgresora del periodismo. En Nómadas del oficio de la palabra (2014) se apuntaba que los rumbos de la práctica periodística no solo estaban señalados por los reacomodos que la tecnología estaba marcando en sus nuevos protocolos de comunicación, sino que la incidencia estaba orientando a una transformación del texto en su escritura, lo que significaba tender un abanico de posibilidades que brindaran las mejores alternativas para atrapar a un lector que día con día se escapa.

El estudio empírico tuvo su concreción en la obra Ojos que miran el mundo: prácticas de periodismo contemporáneo (2019). El trazo fundamental estaba puesto en la narrativa periodística breve y la opinión, como recursos técnicos que abren cauces de lectura. El resultado fue un índice de textos periodísticos escritos, donde los géneros fueron creados con una tesitura de compleja clasificación. Un poco en la idea de Kapuscinski (2010), cuando se alegró de encontrar, en una librería estadunidense, sus obras catalogadas en distintas áreas del conocimiento. Más allá de los géneros, los escritos periodísticos 
apuntaban a una dimensión profunda que no señala solo al texto en su escritura, sino a su origen, creación y lectura como un proceso que es transversal a la estética. Esto colocaba al acontecimiento en un territorio sin límites para su estudio, cuyas formas se advierten y se dibujan en la templanza del periodista como investigador-escritor.

La recuperación teórico-metodológica del estudio se vierte en este escrito que ahonda en algunos elementos clave de la práctica periodística y, con ello, se enfatiza en un trazo que hace una parada en la dimensión estética para su discusión académica. El trabajo que aquí se presenta inquiere en la noción del arco estético que mina el proceso periodístico; esto refiere a la construcción de una punta de lanza teórico-metodológica que focaliza la intención de la estética como recurso transversal en el proceso periodístico. Este arco tiene tres puntos de referencia: la dimensión prosaica del discurso social, la semiótica del texto periodístico y la poética del discurso periodístico.

\section{Metodología}

La investigación parte como un proceso cualitativo exploratorio, sobre una perspectiva sociocultural que delinea un horizonte, con la posible incidencia de transformación en su propio desarrollo. Esto significa que el investigador-académico posibilita sus recursos con relación a los rasgos del acontecimiento que le demarca panoramas inesperados. De la experiencia enunciada se presenta una cartografía teórica metodológica, que al amparo de la hermenéutica y la teoría fundamentada (Álvarez-Gayou, 2003) da cuenta de los referentes clave del estudio.

Ricoeur (2000) estima que "incumbe a la hermenéutica reconstruir el conjunto de las operaciones por las que una obra se levanta sobre el fondo opaco del vivir, del obrar y del sufrir, para ser dada por el autor a un lector que la recibe y así cambiar su obrar" (p.114). La hermenéutica aquí se muestra como una lente que atraviesa el desarrollo de todo el proceso. No se trata de liberar el proceso de sus rigores, sino de proporcionar al estudio periodístico diversas rutas de interpretación del acontecimiento. "Lo importante, desde ahí, es la interpretación del investigador sobre las interpretaciones de los otros que se inscriben en el fenómeno (pues, que quede claro, el investigador no está, no puede estar, fuera del marco de interpretación” (Orozco \& González, 2015, p.104). 
Por otro lado, la teoría fundamentada se traza como una deriva de los datos obtenidos en el trabajo de campo, entendiendo la teoría como un esquema abstracto y analítico de un fenómeno (Álvarez-Gayou, 2003). El estudio que aquí se muestra se sostiene en una heurística de trabajo que se orienta hacia dos fases: la investigación-escritura de los textos periodísticos y la recuperación de la experiencia en su revisión teórica. La espacialidad del estudio se sitúa en Tabasco-México y la temporalidad del estudio transita de 2008 a 2020 , en un proceso que paulatinamente ha ido abonando reflexiones y referentes que lo sustentan.

\subsection{Primera fase: la escritura de textos periodísticos: en busca de la re- flexión lectora (2008-2013)}

¿Cómo se demarcan los acontecimientos para su escritura? Las vivencias sociales son un referente esencial en la ruta periodística, ya que desde aquí llegan al oído del periodista-investigador; la importancia de la selección de los acontecimientos periodísticos queda señalada en la polifonía de voces con la que se revive por la comunidad. El discurso social sin duda proviene de una fuente natural para el ejercicio del periodismo, pues su riqueza de información puede abrir rutas interminables de textos que llegan a los ojos lectores. El ensamble de un proceso de investigación que procede a un texto torna, de forma inherente, un ángulo hacia las potencialidades heurísticas del periodista; estos recursos permiten que el proceso tenga dinámicas más abiertas, es decir, el periodismo encuentra un acomodo confiable y natural en la hermenéutica, perspectiva que brinda al investigador miradas más agudas y sensibles del quehacer. El marco de temporalidad de esta fase fue del año 2008 al 2013. De este periodo de investigación, además de los textos escritos, surgió el texto académico: Al encuentro del oficio periodístico. El procedimiento metodológico de la práctica de campo se instaura de la siguiente forma:

\subsubsection{El aconteimiento rumbo a la escritura}

Los criterios de selección del acontecimiento se abren con cierta arbitrariedad, que al paso del tiempo quedan en dos rutas; por un lado, el hecho periodístico en su carácter replicante, es decir, el relato contado oralmente y 
repetido en muchas voces. Por otro lado, está el suceso puesto como noticia, cuyo impacto abre a la discusión social. En ambos casos la información estaba determinada por el impacto que tuvo como discurso social. Estos criterios que marcaron los umbrales del trabajo se resumen de la siguiente manera:

a) El acontecimiento contado oralmente (historia oral), de temporalidad reciente y de impacto en las comunidades de Tabasco.

b) Hechos puestos como noticias en diferentes medios periódicos que hacían eco en la comunidad tabasqueña, así como en las redes sociales.

De lo anterior se fue procesando un índice de sucesos que fueron tomados de acuerdo al interés público mostrado. Se publicaron 124 textos escritos en diversos medios (impresos y digitales), sobre un promedio de un texto semanal.

\subsubsection{De la información al texto}

Mucho del interés periodístico llega desde algunas fuentes que lo vivieron o escucharon. Una llamada telefónica, una plática, una lectura de medios es propicio para agudizar los sentidos periodísticos. Dos recursos etnográficos emergen bajo los cauces de la investigación:

- La recuperación de la información que arriba de muchas formas, desde la historia oral, hasta documentación que revive la memoria. El viejo cuaderno de notas o los apuntes guardados en el teléfono, así como la grabación de audios o videos sobre el hecho y los informantes, además de la entrevista, son recursos que se convierten en referencias legítimas de la memoria.

- La observación penetrante e intuitiva con la que se sobremira el acontecimiento en perspectivas inusitadas, y guardadas en la memoria, misma que alimentará los sobregiros estéticos. 


\subsubsection{Valoración y escritura del texto periodístico}

¿Cómo se desenvuelve el investigador-escritor en esta etapa? Esta quizás sea una de las partes más complejas en la tarea periodística, pues en ella no solo se determina el rumbo de la información, sino la creación del texto. La valoración del acontecimiento, sobre un diagnóstico de la información que se posee, puede determinar, además del tipo de lenguaje (visual, auditivo multimedia, escritura o género), su presencia o ausencia en un determinado medio periodístico.

Reyes (2007) enuncia con mucha claridad que el proceso de la escritura tiene algunos puntos clave. Por un lado, está la idea literaria, como el momento donde emerge algo que merece cultivarse -o que también puede morir-; y la magia literaria, como el momento donde se toma claridad para que la idea florezca. En ambos momentos no hay fórmulas, solo un marco de sensación alentadora del escritor. Estas etapas pueden agruparse en la denominada "fase embrionaria", que es un momento clave del escritor para concretar el desarrollo de un texto.

Las posibilidades de engranar la información en un texto no están dadas por la abundancia, sino por la capacidad articuladora del escritor de armarla en una trama periodística relativamente breve. Este es el primer paso de una heuresis del periodista para comprender el desarrollo de un texto de acuerdo con los valores del momento en que se produjo. Esto define el rumbo de un contenido, que tiene tres claves a seguir: la brevedad, la cotidianidad del discurso social y la provocación de la reflexión.

\subsection{Segunda fase: la revisión teórica a partir de la recuperación de la experiencia periodística (2014-2020)}

Es durante esta etapa que se abona y se inquiere la reflexión teórica que abre diversas aristas de cavilación; se presentan como los nudos clave de la práctica periodística, mismos que a la postre pueden funcionar como orientadores de una pedagogía para la enseñanza del periodismo. Durante este periodo aparecieron dos de los textos ya mencionados: Nómadas del oficio de la palabra y Ojos que miran el mundo: prácticas de periodismo contemporáneo. En ambos trabajos ya se avizoraban algunos trazos teóricos que arribarán a este artículo como explicaciones académicas. 
La noción de teoría que orienta este trabajo es simple: esta se entiende como una manera de ver la realidad. Una teoría es un mundo que se abstrae en una forma de pensar única y valiosa, no solo para la ciencia, sino para la humanidad. Hombres y científicos que no elaboren teorías, condenan al conocimiento y a las instituciones a un pensamiento dogmático. En alusión a ello, Einstein, en palabras de Martínez-Miguelez (2012), refería:

Crear una nueva teoría no era como erigir un rascacielos donde había un viejo granero; era, más bien, como escalar una montaña, logrando una visión nueva y más amplia y descubriendo conexiones inesperadas entre nuestro punto de partida y su rico entorno (p.125).

Por su parte, Nicolescu (1996) concibe a la teoría de la siguiente forma: "Ahí donde la teoría deja de ser teoría y se convierte en su verdadera raíz etimológica referida como contemplación" (p.58). Es en esta tesitura como se retrae una abstracción pensada desde la experiencia transdisciplinaria, una tarea que se soporta en la movilidad del pensamiento de ida y vuelta. Es cabal en la investigación de los estudios periodísticos, que los procesos sean puestos en la mesa de la interpretación, un complejo nudo que se concibe como una introspección reveladora, no de los textos, sino de la lectura inquisitiva y profunda de la que procede.

Es con esta mirada de la teoría con la que se corren los riesgos para desarrollar un esquema teórico-metodológico. Este, a su vez, se construye sobre la referencia etnográfica de la práctica de campo. La tangente se traza en los confines del mismo proceso de investigación, al amparo de la teoría fundamentada. En esta deriva teórico-periodística aparece así un arco estético, noción categorial cuyos pliegues modelan la incidencia de los "sentires" puestos en el trayecto periodístico.

\section{Resultados}

Ilustrar el proceso periodístico sobre la idea de un proceso teórico, requiere entonces de acercarse a la explicación de arco estético como categoría directriz del estudio. ¿Cuál es la noción que se abstrae de esta categoría? El arco en algunas genealogías de la cultura, según Moulian \& Garrido (2015), refiere a: 
Un espacio de interconexión entre los niveles del cosmos, por el que transitan las entidades espirituales y a través del que es posible acceder o comunicarse con ellas (...) Por su textura nodal, permite observar el correlato de paradigmas cosmovisionarios, es decir, de los metamodelos (modelos de modelos) sobre el universo en aspectos como su diseño, los niveles que lo conforman, las interacciones, espacios y modos de conexión entre estos, las entidades que los habitan y sus desplazamientos (..). Su trazado simbólico constituye un umbral que delinea a la vez que permite trascender los puntos de demarcación que señalan la frontera entre distintos planos y niveles de realidad (pp. 213-223).

Las interconexiones establecidas en la noción de arco pueden entenderse desde la estética como la dinámica o movilidad de los sentidos que se ponen en juego. Mandoki (2006) explica estos intercambios como "procesos en los cuales un sujeto se pone en relación con otros sujetos y su medio ambiente a través de una gran variedad de recursos" (p.18). La autora (2006) traza, desde el marco de la socio-estética, dos conceptos clave para su estudio: la poética, como las prácticas de producción y recepción en el arte; y la prosaica, entendida como las prácticas de producción y recepción estética en la vida cotidiana. Ella formula una especie de cartografía con dos coordenadas para la explicación de los intercambios: la semiótica y la estética.

En el encuentro de estos dos surcos conceptuales (arco y estética) emerge el arco estético, que se comprende como una representación o espectro que dibuja un metamodelo del acontecimiento, interconectado con el texto periodístico y la poética abierta por el lector a través de la recepción del texto. El desplazamiento del proceso periodístico se puntea, en el imaginario, sobre una tangente del acontecimiento que pasa y recorre, como discurso, los diversos planos de realidad hasta llegar al lector. Lo que se articula es un arco que relaciona diversas cosmovisiones del mundo, que son permeadas de sentidos cuyo modelaje se brinda en la templanza del periodista (ver Figura 1). 


\section{Figura 1}

\section{Arco de la dimensión estética en la práctica periodística}

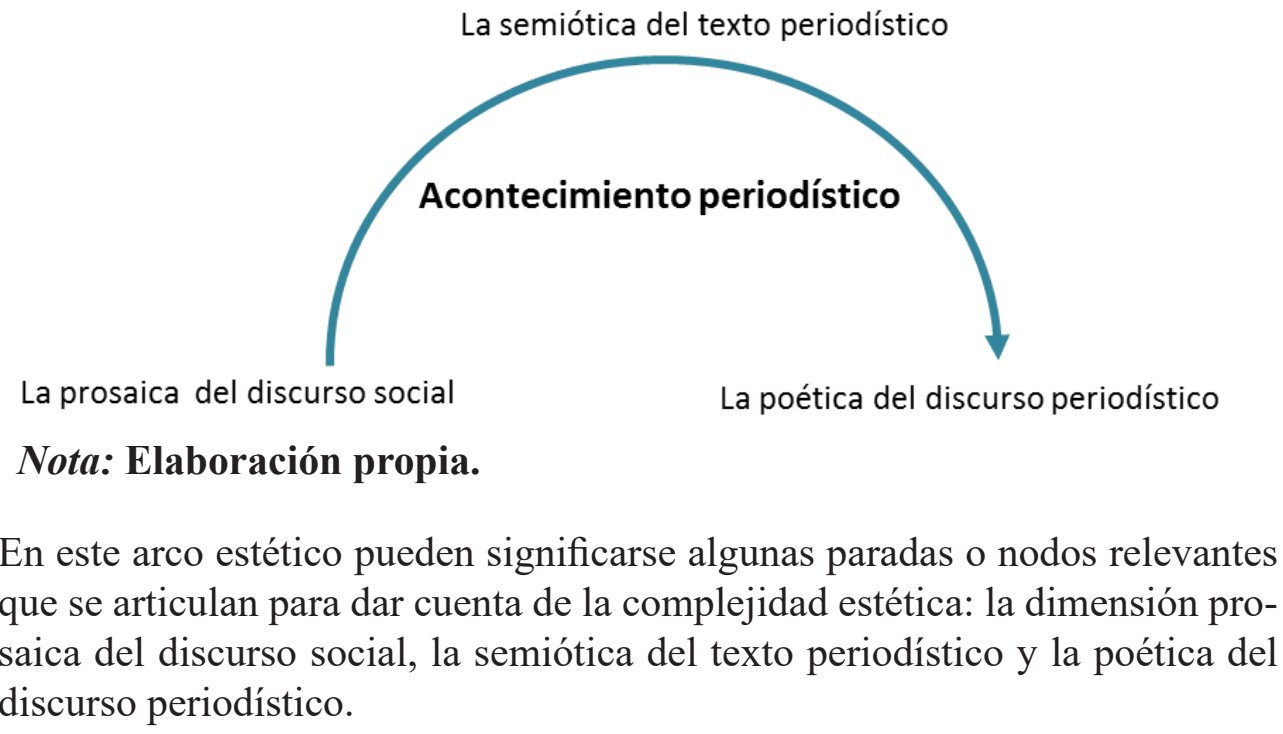

\subsection{La prosaica del discurso social}

Las precondiciones y condiciones del acontecimiento pueden definirse como avistamientos epistemológicos o de origen, y constituyen el nivel donde se instaura el discurso social, cuyo proceso de mediación es la enunciación. Son las fuentes las que fundan el "manicomio" de la información; estas fuentes sociales hacen una puesta discursiva-enunciativa, cuya matriz histórico-cultural libera e instituye también el lenguaje estético. El investigador-periodista se enfrenta así a un mundo caótico vertido en fuentes que aseveran o niegan la información. Aquí subyace una estesis que constituye la matriz social que alimenta el acontecimiento periodístico. El ámbito está "matriciado" con la multiplicidad de sentires con los que se visiona y explica el hecho periodístico. Son voces, relatos, llamadas, imágenes... todas esas polifonías que aglutinan una arquitectura noticiosa. Explica Mandoki (2006) que:

La prosaica es la teoría de las sensibilidades sociales y del papel de la estesis en las estrategias de construcción e intercambio de identidades individuales y colectivas (...) Es la exploración de actividades estéticas 
materializadas en procesos de construcción de realidades matriciales y sus respectivas identidades (p.16).

Es evidente que, en el lenguaje estético, hay una condición enunciativa que posibilita el discurso social. Greimas \& Fontanille (2009) explican el recorrido, en su condición de semiosis, como:

Un camino marcado por hitos, pero, sobre todo, como un flujo coagulante del sentido, como un espesamiento continuo, a partir de la confusión original y "potencial" para llegar por medio de la "virtualización" y “actualización", al estadio de la "realización", pasando así de las precondiciones a las manifiestas discursivas (p.12).

En este nivel del arco estético se despliega, entonces, todo el potencial discursivo que encaminará su ruta, sobre la fuerza (fluxión) de su enunciación. Desde aquí se despega el sentir que será transferido en las apropiaciones del investigador-escritor.

\subsection{La semiótica del texto periodístico}

Este enclave representa el movimiento del texto frente al autor, lo que implica la interrogación del escritor al discurso social, para elaborar una estructura narrativa y/o de opinión que se forma sobre las bases de las reglas textuales donde se inscribe. El texto aquí se concibe como un constructo de signos que dan cuenta de una mirada del mundo. Este estado de estesis que concurre en el texto es explicado por Kapuscinski (2006) como una actividad del pensamiento:

En nuestra mente existe una inmensa interacción entre lo que a veces es percibido de forma inconsciente -influye, sin embargo, en nuestra fantasía-, nuestro modo de observar el mundo y nuestra creatividad, hasta el punto de que cada vez se hace más difícil trazar una línea que delimite lo que nos pertenece a la imaginación, a los descubrimientos y a las creaciones de los demás (p.103).

Aquí se actúa sobre lo que Reyes (2007) denomina "la magia", como una función catártica de la idea. Indudablemente que el periodista no es ajeno a una carga de sentidos que lo distinguen y que provienen del intercambio o 
interacción con los otros sujetos. El texto es una representación de signos que son portadores de la dramática que caracteriza a la estética. En el campo periodístico, son modos de describir la realidad. El texto no es más que una postura hermenéutica del escritor-investigador, donde sus posibilidades creativas se ven concretadas en un tejido de signos que aluden a sus sensibilidades. Eco (1992) lo explica de la siguiente manera:

Puede ocurrir que los elementos de indeterminación, ambigüedad, casualidad, que ciertas obras de arte reflejan en su estructura, no tengan nada que ver con posibles "estructuras metafísicas" de la realidad, supuesto que estas puedan objetivarse y describirse de modo irrefutable; lo que no quita que estas nociones se infiltren en nuestro modo de ver el mundo (p.24).

El proceso exegético del autor frente al texto correspondería a lo que Greimas \& Fontanille (2009) denominan el desarrollo narrativo:

Que puede ser explicado como una segmentación de estados que se define únicamente por su "transportabilidad". El horizonte de sentido que se perfila detrás de una interpretación como esta, es el de un mundo concebido como discontinuo, lo cual, por lo demás, corresponde, en el nivel epistemológico a la instauración del concepto indefinido de "articulación”, primera condición para poder hablar del sentido en cuanto a significación (p.10).

La transportabilidad y articulación de las que hablan Greimas y Fontanille es la información que arriba y que, tras un éxodo y filtraciones de sentidos, se torna en representaciones, fantasmas que la memoria y el pensamiento vitalizan. El texto aquí se deja ver como una estructura manifiesta, producto de una postura hermenéutica del escritor-investigador. Si bien las posibilidades creativas se ven armadas en un tejido de signos, el texto también es revelador de lo que Greimas \& Fontanille (2009) denominan el "horizonte óntico", donde se puede interrogar el discurso inmanente y dar cuenta en cierta medida del "ser". Es decir, el texto es también revelador de una transferencia de sentidos estéticos que se acunan en el encaje de la poética.

El autor-escritor queda representado, entonces, en un universo poético en el que subyacen no solo los niveles de realidad donde se evoca el aconteci- 
miento, sino también los del autor mismo. El texto se muestra con formas retóricas, en cuyo tejido se acunan géneros ${ }^{1}$ o a-géneros ${ }^{2}$, que aluden a un muestrario de técnicas con las que el autor traduce su propia dramática de la realidad periodística. Desde aquí el autor encarna su propia poética, que se deja ver en forma de discurso. Ricoeur (2000) lo describe como la conducción de un antes y un después del texto. En el texto, se quiera o no, corre un universo afectivo personal o impersonal. El éxodo de esta poética se encamina hacia la exégesis del lector.

\subsection{La poética del discurso periodístico}

Este nivel corresponde al lector. El lector lee un texto sobre el que emerge un tamiz de sentires procreados desde el autor; un tejido que va transitando con la emocionalidad de los otros. Los intercambios estéticos van y vienen desde el discurso social, hasta la recepción del lector. Jauss, retomado por Lizarazo (1998), explica que en la recepción de un texto interviene la imaginación del lector, pues es él quien le da vida al texto.

Eco (1992) dice que la obra de arte se entrega como "el único modo que le es posible, bajo un carácter imaginativo, ofreciéndonos imágenes del mundo que equivalen a metáforas epistemológicas, y constituyen un nuevo modo de ver, de sentir, de comprender y de aceptar un universo" (p.24). Este acto de interpretación del texto, por parte del lector y bajo la batuta de la significación, está impregnado de sentires. El lector hace de un texto, más allá de acto de inteligencia, un encuentro de linaje con el autor que le remite a las transferencias de otras experiencias de la emoción. "Leer es, en suma, activar el potencial de un enorme reservorio de emociones, ideas, vivencias que la cultura escrita y, a partir de un ejercicio de atención e inteligencia, prolongarlo, fertilizarlo, hacer que sea, como el amor para Quevedo, contante y más allá de la muerte" (Goldin, 2007, p.9).

La dialéctica de este proceso es señalada por Ricoeur (1999), cuando discute con relación al proceso de interpretación de los textos. El autor enuncia

1. Narrativa, ensayo, artículos de fondo, cuento, etc.

2. Estilos que rompen con la frontera de géneros, es decir, se hibridan o mutan. 
que en todo acontecimiento explicado (autor) hay un sentido que busca la comprensión (lector). El lector percibe, por tanto, un acontecimiento en el que puede solidarse con el dolor, la alegría, el triunfo, la pasión; es una carga de sentidos que no están ajenos al autor o a las voces cercanas al acontecimiento. En el texto se lee una poética que se transforma en el propio sentir del lector. El evento periodístico fluye como una flecha que va catalizando los sentires, desde el discurso social hasta el lector. Ricoeur (2000) reflexionó sobre este proceso interpretativo en la noción de la triple mímesis, un cauce que puede auxiliar en la explicación de cada uno de los niveles o nodos del arco estético.

\section{Discusión}

¿Por qué estudiar la dimensión estética en el periodismo? Como ya se ha mencionado, si la naturaleza transgresora del periodismo busca otras alternativas, entonces este ángulo ofrece aristas interesantes que pueden conducir a exploraciones inusitadas. Quizás la respuesta la brinda con mucho énfasis Perniola (2008), cuando dice que:

El sentir ocupa en nuestra época un lugar distinto al que ocupó en otros momentos del pasado (...) Todo indica que, en el plano del sentir, nuestra época ha ejercido su poder. Cabría definirla, por tanto, como una era estética; pero no porque tenga una relación privilegiada y directa con las artes, sino, más específicamente, porque sus campos estratégicos no son el cognoscitivo ni el práctico, sino el del sentir, el de la aisthesis (p.27).

Lo cierto es que el estudio del periodismo anida infinidad de paradas; los procesos de interpretación son asuntos complejos que instan en muchos casos a tomar posturas conservadoras o radicales. Más allá de tomar estas posturas o cuestionarlas, lo significativo en lo académico es examinar diversas lentes que ayuden a que la práctica tenga su encuentro con lectores que cada día son más huidizos. Estudiar el frente estético, no solo como un recurso de arte en las palabras, sino también como la comprensión del sentir, como un lenguaje que corre en la ruta del acontecimiento, brinda claves importantes en el estudio del periodismo. La trama de sentidos que se ponen en juego es la triada de actos entre el discurso social-el abordaje de un texto-la lectura. En este proceso se esboza un arco que coloca en relevancia la estesis del acontecimiento 
vivido por una comunidad, es decir, más allá de un texto periodístico, hay entresijos que requieren de otros abordajes.

Por debajo de la persistencia de un género, de una forma, de una disciplina, de una actividad teórica, se trata ahora de detectar la incidencia de las interrupciones, interrupciones cuyo estatuto y naturaleza son muy diversos. Actos y umbrales epistemológicos, descritos por G. Bachelard: suspenden el cúmulo indefinido de los conocimientos, quiebran su lenta maduración y los hacen entrar en un tiempo nuevo, los escinden de su origen empírico y de sus motivaciones iniciales: la carga de emocionalidades en un acontecimiento constituye un universo particular que bifurca la realidad en planos divergentes (Foucault, 2007, p.4).

El arco estético es esa flecha que demarca las conexiones o interconexiones de los sentidos que se bosquejan cuando el acontecimiento llega al lector. Adentrarse en esta ruta significa explorar un territorio casi olvidado por el periodismo -en los límites que la modernidad le adjudicó a la práctica-, pero, sin duda, esta ruta apela a otras interpretaciones u otras escrituras y, por supuesto, a la comprensión de otro tipo de lector, receptor, usuario, audiencia de periodismo. Esta heurística permite escudriñar un recorrido donde la estética acompaña a la práctica periodística, y con ella se intenta abstraer y comprender su condición de sentidos:

La hermenéutica (...) se preocupa de reconstruir toda la gama de operaciones por las que la experiencia intercambia obras, autores y lectores (...) Lo que está en juego, pues, es el proceso concreto por el que la configuración textual media entre la prefiguración del campo práctico y su refiguración por la recepción de la obra (Ricoeur, 2000, p.114).

En este sentido, emergen figuraciones que brindan claves por donde atraviesa el acontecimiento periodístico.

\subsection{La comunidad del acontecimiento}

¿Qué es un acontecimiento? Una definición donde el concepto se asume como temporalidad es la que describe Rancière (1996): "un acontecimiento solo existe retrospectivamente, cuando ya se ha andado el camino" (p.21). 
En tanto, Jodelet (2008) lo explica como "irrupción inesperada en un orden temporal y un estado de cosas" (p.54). Por su parte, Foucault (2007) lo aborda con los rasgos de un movimiento discursivo que irrumpe en el espacio- tiempo, causando una trama de efectos y un tejido de relaciones:

(...) no es ni sustancia, ni accidente, ni calidad, ni proceso; el acontecimiento no pertenece al orden de los cuerpos. Y sin embargo no es inmaterial; es en el nivel de la materialidad, como cobra siempre efecto, que es efecto; tiene su sitio, y consiste en la relación, la coexistencia, la dispersión, la intersección, la acumulación, la selección de elementos materiales; no es el acto ni la propiedad de un cuerpo; se produce como efecto de y en una dispersión material (p.57).

El acontecimiento periodístico puede entenderse, en los términos del lenguaje, como un discurso que irrumpe la continuidad espacio-temporal de un orden social, que sobre movimientos multiformes es portador de referencias, ideologías, y sentires. El acontecimiento periodístico per se, puede ser un lenguaje explícito, pero también resguarda herméticamente -entre las diversas aristas- otros lenguajes. Si el acontecimiento periodístico es un discurso, entonces este se plantea ante el periodista como un horizonte de búsquedas de las unidades que lo conforman. Foucault (2007) lo coloca y lo lleva también al terreno de lo no dicho:

Todo discurso manifiesto reposaría secretamente sobre un "ya dicho", y ese "ya dicho" no sería simplemente una frase ya pronunciada, un texto ya escrito, sino un "jamás dicho", un discurso sin cuerpo, una voz tan silenciosa como un soplo, una escritura que no es más que el hueco de sus propios trazos. Se supone así que todo lo que al discurso le ocurre formular se encuentra ya articulado en ese semisilencio que le es previo, que continúa corriendo obstinadamente por bajo de él, pero al que recubre y hace callar (p.40).

Justo en ese discurso recubierto se anidan los sentires que vivifican la dramática de un acontecimiento periodístico. Está en el eje de lo simbólico. Un grito, una mirada, un sonido, un movimiento corporal asientan el sentir del que es portador el acontecimiento a través de quienes lo viven y lo reviven en la memoria. Mandoki (2006) lo plantea desde los registros de la estética: la proxémica, la cinética, la enfática y la fluxión. El espacio-tiempo donde ocurre el acontecimiento periodístico no está desprovisto de miradas y escuchas 
que son afectivas o emocionales; por otra parte, son los registros retóricos los que naturalizan lo explícito.

La forma en que se hilvana la trama está compuesta de alegorías emocionales que reviven el momento. Dolor, risas, llantos, espantos, son cargas vociferadas en tonalidades o gestualidades que se invisten de fuentes de información. Pasión, vida y muerte son el pathos que se arraiga en el acontecimiento y llega al hombre de la tienda, a la vecina, al familiar, a quienes reviven el relato con las palabras, con el cuerpo y el escenario; estos implican sentires que alimentarán la mirada del periodista.

Así pues, hoy nada es ajeno al sentir. Sin embargo, ya no le corresponde a la subjetividad individual el honor de pasar en primera persona y sin protección por esta experiencia. El sentir ha adquirido una dimensión anónima, impersonal y socializada que reclama ser reafirmada (Perniola, 2008, p.29).

La animosidad, afectividad o pasionalidad son sentires que se colocan en la lupa de un periodista de forma yacente o subyacente, lo que insta a ser reflexionado. Freud (1999) argumentaba que "olvidar la abigarrada variedad del mundo humano y de su vida anímica, pone en peligro los valores genuinos que la vida ofrece" (p. 7).

\subsection{El investigador-escritor del acontecimiento}

El rol de la figura investigador-escritor no se presenta fácil de explicar, sobre todo cuando la historia o las reglas, es decir, el canon de la práctica, ha desestimado el discurso estético, desde el sentir de "los otros" hasta el sentir del periodista.

El género se coloca como un recurso que pareciera delimitar la frontera entre lo objetivo y subjetivo del texto periodístico. Sin embargo, no se puede negar que en los subrepticios de cualquier texto se infunde una estesis social que pasa por el sentir del periodista. Capas sedimentas de emocionalidades son reticuladas por un escritor que cuenta o reflexiona el relato-suceso. Kapuscinski (2010) devela este mundo un poco caótico y la manera en que lo enfrenta el periodista: 
El que, por el contrario, escribe sobre el mundo de aquí y ahora, en el que todo cambia, todo fluye y todo resulta frágil y efímero, se las tiene que ver con un manicomio en el cual se ha producido una rebelión de sus pacientes, se ha declarado un incendio, los sótanos están anegado y la situación cambia cada cinco minutos. Por eso resulta tan difícil retratar el presente (p.83).

Esta figura es un lector-intérprete de la realidad, o como pudiera verlo Steiner (2007), el disciplinado entendimiento del entendimiento es clave en esta discusión que pone en la mesa de análisis el uso de la información y la forma en que esta es transformada; un juego donde la realidad de unos adquiere otro plano de realidad en la poética del texto. El vínculo entre el suceso y el texto es mediado por el investigador-escritor que purga, no solo la emocionalidad revivida en las diversas fuentes, sino además su propia condición de intérprete de la realidad. La solidaridad, el desapego, el triunfo, la venganza como móviles de una noticia, van cargados de empatía, furia, risa, llanto, dolor, entre otras cargas de sentido. Son fuentes emocionales que se escudan en la retórica de un texto que se brinda como crítica, reflexión, narración, valoraciones, etc.

\subsection{El lector del acontecimiento}

El acontecimiento periodístico permeado de sentires, tras una elaborada poética, arriba para su lectura y su encuentro con el lector. Es una ruta cuyos lazos invisibles del sentir se naturalizan en una transferencia de sentidos e intensidad (Kristeva, 2009). Mandoki (2006) también lo discute con los intercambios estéticos en el registro de la fluxión. En este esquema de transferencia del sentido, dice Kristeva (2009) que se establece una dinámica de tres: el Sujeto, el Objeto y el Tercero. El Objeto es el imaginario, es el drama intersubjetivo (la dramática, en Mandoki).

Por el contrario, se abre esa pasión de los signos que son la libre asociación, el desplazamiento, la condensación, etc., resumiendo, una literatura privada de público a la vez que priva de código social, pero sin embargo son tan turbadora e intensa como los efectos catárticos del gran arte (Kristeva, 2009, p.11). 
Un hombre sentado en el sofá de su casa, leyendo el periódico, o un joven mirando un acontecimiento en la televisión, son imágenes que, como explicaba Steiner (2007), son productos y generadores de un orden social y moral. Esta referencia imaginativa ahora mismo tiene otras disrupciones. El lector de hoy quizá sea la figura más compleja de entender, sobre todo porque las encomiendas periodísticas se ven amenazadas con un sujeto que le rehúye, un lector fugaz en sus búsquedas lectoras. Este lector es un errante, en muchos casos es un trotamundos cibernético, un nómada que está muy cercano a una megapantalla que le ofrece otros vectores de lectura. Sobre esta bandada seductora de otras lecturas, Bauman (2013) señala:

Que la cultura se asemeja hoy a una sección más de la gigantesca tienda de departamentos en que se ha transformado el mundo, con productos que se ofrecen a personas que han sido convertidas en clientes. Tal como ocurre en las otras secciones de esta megatienda, los estantes rebosan de atracciones que cambian a diario, y los mostradores están festoneando con las últimas promociones, que se esfuman de forma tan instantánea como las novedades envejecidas que publicitan (p.21).

Justo en este punto crítico es donde el acontecimiento periodístico plantea su ángulo más endeble. Ahora mismo se habla de una crisis de lectura donde la información periodística se llena con un tuit o mensaje instantáneo a través de un teléfono y donde la confianza en el medio o periodista se encuentra en encrucijadas con horizontes inciertos. El mismo Steiner (2007) se cuestionaba si de verdad estaba leyendo menos la gente. Tal vez la pregunta sería: ¿qué y cómo está leyendo la gente? Steiner (2007) explica que se lee (en el sentido genérico del término lectura) más música que libros, quizás porque la música permite esa democracia de la emoción que la literatura difícil se niega; asevera que la lectura de hoy es ad hoc y fragmentaria.

La compleja demarcación del texto-lector encierra un escenario cultural y social que ha gastado mucha tinta en las reflexiones donde se discute la lectura. Lo efímero, tal como lo plantea Lipovetsky (2009), parece también gobernar al lector de acontecimientos periodísticos. La ligereza, la vaciedad, la difuminación o pérdida de la referencia y del contexto, conducen a un periodismo que abre una brecha cada día más distante entre el periodismo y sus lectores.

Hoy en día el periodismo, en cualquiera de sus maneras de vehicularse (mediación), presenta desafíos que demanda a sus estudiosos buscar rutas emer- 
gentes con relación a los escenarios en que se inscribe, lo que significa tener enfrente retos trascendentes. Su naturaleza transgresora es una provocación para estudiar el devenir epistemológico y social de la práctica. Dice Ricoeur (2000) que "entre la actividad de narrar una historia y el carácter temporal de la existencia humana existe una correlación que no es puramente accidental, sino que presenta la forma de necesidad transcultural" (p.113).

\section{Conclusiones}

El estudio del periodismo incita quizás a ser un poco iconoclasta, en esa definición de heterodoxo, irreverente o revolucionario; lo que significa estudiar el periodismo desde diferentes campos teóricos y metodológicos. Si bien se trata de analizar las tradiciones canónicas, es pertinente también explorar nuevas rutas.

Steiner ya hablaba respecto al uso de las palabras (tarea del periodismo) como un lenguaje más frágil y menos cómodo con nuestras necesidades de antes, lo que sin duda pone el nudo del análisis en las formas de hacer periodismo en la actualidad. Steiner (2007) agregaría: "Esta brutalización o profanación de la palabra es muy probablemente una de las causas principales de la marea de autodestrucción, ya sea del silencio autoimpuesto o del verdadero suicidio" (p.289).

En el mito de Psique y Cupido (Eros), la cultura griega colocaba una narrativa en la que figuraban dos rasgos de la naturaleza humana. La emocionalidad, a través de la representación de Cupido, quedaba señalada como un atributo inherente a la vida misma. ¿Por qué no estudiar la dimensión estética en el periodismo, si la labor periodística está inmersa en la exploración de la vida misma? Lo que aquí se trae entonces es un acercamiento a la dimensión estética en la travesía de la práctica periodística. Foucault (2007) concibe la historia de las mentalidades como monumentos arqueológicos portadores de la memoria de cada época, mentalidades que se erigen como dominantes en cada tiempo. En el telón del estudio de la estética en el periodismo, esto significa dar cuenta del sentir que rige cada pueblo, en determinado tiempo-espacio.

El estudio de la emocionalidad es visto por Ferres (2014) como "un mundo cerrado y aparentemente sin salidas, que invita al juego, a perderse, a aban- 
donarse, pero es también, por su complejidad, es un reto a la inteligencia, un desafío a la búsqueda de salidas" (p.19). Lo anterior implica que su exploración se hace necesaria en la interrogación del camino y los cruces de un acontecimiento periodístico. Escindir el análisis del sentir que transita en la ruta de un acontecimiento ha omitido una mirada importante en la reflexión de la práctica, sobre todo porque se niega al periodismo una mirada relevante en la comprensión de sus entretejidos. Reconocer el sentido de una prosaica y una poética que soporta el texto periodístico, es dar un gran paso hacia el encuentro con el lector.

El arco estético es ese recorrido que despliega un macro o microedificio sensitivo, cuya explicación revela la importancia de la estética como una perspectiva que inquiere el sentir en la vida humana. El acontecimiento periodístico es, así, el discurso que traza una ruta estética. En tal recorrido se implica a:

- Los actores de una comunidad, cuyo discurso afectivo fluye sobre los andamios de la retórica social con la que se reviste una prosaica como de fuente de emocionalidades.

- La apropiación o distensión que hace el periodista, en la elaboración de una semiótica que inviste un matiz poético con el que arriba al lector a través de un texto periodístico.

- Un lector que recibe un tejido de la realidad en el que se acusa un acontecimiento sensible a su propio sentir, lo que pasa a ser reinterpretado a su manera.

Este espectro estético, reconfigurado como un metamodelo, aloja las afectividades de un trayecto social-cultural. La prosaica del discurso social, la semiótica del texto periodístico y la poética del discurso periodístico, establecen la explicación de esta travesía discursiva, donde la estética se convierte en una fuente de experiencias a veces negada por la práctica periodística. Entender y reconocer este arco, provoca también:

- La posibilidad de realizar análisis de lo que ocurre y discurre en un acontecimiento, desde el sentir de sus estructuras sociales (comunidad-periodista-lector).

- La intención de recuperar la memoria sentida de los acontecimientos periodísticos, desde la cual se perfila también la historicidad del relato. 
- La necesidad de contar otras historias donde el recuerdo cultural y social tienen una diáspora de emociones que hace su propia dialéctica con el lector.

- Comprender la idea de una transferencia de sentidos, que es portadora de cargas emocionales.

- Repensar el sentir del acontecimiento periodístico como emocionalidades o afectividades.

- El análisis de un recorrido en el que cada nivel provee un edificio de significaciones propias.

- La reconstrucción de la vida cotidiana en su condición sensible, frente al autor y el lector de textos.

El quehacer no termina aquí, por el contrario, es importante seguir elaborando preguntas. Una de ellas sigue siendo clave para los estudios periodísticos: ¿cómo renovar entonces una práctica que tiene un escenario social de transformación continua? Los debates alrededor de este quehacer deben permitir un abanico de reflexiones que le abonen o provoquen otros estatutos periodísticos. No es nuevo que el periodismo históricamente haya buscado otros lenguajes para acercarse a su lector. Ahora mismo el uso de las redes sociales está planteando las renovaciones multimedia del lenguaje. Sobre esta vocación transgresora del periodismo se convocaría a escudriñar y deliberar en muchas latitudes: en las formas literarias, semiológicas, fonéticas, iconográficas, antropológicas, psicoanalíticas, históricas, cibernéticas, digitales, entre otras disciplinas o campos de estudio; lo que particular e inevitablemente conllevan a una dimensión estética.

Es importante también repensar la emergencia de la práctica periodística, quizás con una mirada basada en lo estipulado por Wittgenstein (2010), donde se comprenda que las reglas, uso y contexto (juego del lenguaje) están determinando otros protocolos comunicativos, afines a los tiempos actuales. 


\section{Fuentes consultadas}

Álvarez-Gayou, J. (2014). Cómo hacer investigación cualitativa. Fundamentos y metodología. Paidós.

Bauman, Z. (2013). La cultura en el mundo de la modernidad líquida. Fondo de Cultura Económica.

Cassany, D. (2008). Prácticas letradas contemporáneas. Ríos de Tinta.

Eco, U. (1992). Obra Abierta. Planeta-Agostini.

Ferres, J. (2014). Las pantallas y el cerebro emocional. Gedisa.

Foucault, M. (2007). Arqueología del saber. Siglo XXI.

Freud, S. (1999). El malestar en la cultura. Alianza.

Goldin, D. (2007). Liminar. En J. Larrosa (Ed.), La experiencia de la lectura. Estudios sobre literatura y formación (pp. 7-11). Fondo de Cultura Económica.

Greimas, A., \& Fontanille, J. (2009). Semiótica de las pasiones. De los estados de cosas a los estados de ánimo. Siglo XXI-Benemérita Universidad Autónoma de Puebla.

Guillen. E. (2018). Ética y Estética: el periodismo literario como herramienta para narrar historias de la comunidad transgénero [Tesis de licenciatura]. Universidad Juárez Autónoma de Tabasco.

Jodelet, D. (2008). El movimiento de retorno al sujeto y el enfoque de las representaciones sociales. Cultura y representaciones sociales, 3(5), 3263. http://www.culturayrs.unam.mx/index.php/CRS/article/view/535

Kapuscinski, R. (2006). Los cínicos no sirven para este oficio. Sobre el buen periodismo. Compactos-Anagrama.

Kapuscinski, R. (2010). El mundo de hoy. Anagrama.

Kristeva, J. (2009). Historias de amor. Siglo XXI. 
Lipovetsky, G. (2009). El imperio de lo efímero: la moda y su destino en las sociedades modernas. Anagrama.

Lizarazo, L. (1988). La reconstrucción del significado. Addison Wesley Longman.

Mandoki, K. (2006). Prácticas estéticas e identidades sociales: prosaica II. Conaculta.

Martínez-Miguelez, M. (2012). El paradigma emergente. Trillas.

Moulian, R., \& Garrido, C. (2015). Etnopoéticas del umbral: el simbolismo del arco en la cultura mapuche williche y sus recurrencias en los sistemas cosmovisionarios andinos. Estudios atacameños, (51), 207229. https://dx.doi.org/10.4067/S0718-10432015000200013

Nicolescu, B. (1996). La transdisciplinariedad. Ediciones Du Rocher.

Orozco, G., \& González, R. (2015). Una coartada metodológica. Abordajes cualitativos en la investigación en comunicación medios y audiencias de los abordajes. Tintable.

Pérez-Morales, F. (2004). De la historia oral al periodismo literario. Una vía de aproximación a la enseñanza del oficio. Pomares.

Pérez-Morales, F. (2008). Al encuentro del oficio periodístico. En C. García, \& R. Gómez (Eds.), Comunicación e Interdisciplina. UANL-AMICFCC.

Pérez-Morales, F. (2014). Nómadas del oficio de las palabras. En M. Xicotencalt, \& H. Angulo (Coord.), Periodismo por docena. UJAT.

Pérez-Morales, F. (2019). Ojos que miran el mundo. Prácticas de periodismo contemporáneo. Iconos-UJAT.

Perniola, M. (2008). Del sentir. Pre-Textos.

Rancière, J. (1996). El desacuerdo. Política y filosofía. Nueva Visión.

Reyes, A. (2007). Teoría Literaria. Fondo de Cultura Económica. 
Ricoeur, P. (1999). Teoría de la interpretación. Discurso y excedente de sentido. Siglo XXI.

Ricoeur, P. (2000). Tiempo y narración II. Configuración en el relato histórico. Siglo XXI.

Steiner, G. (2007). Sobre la dificultad y otros ensayos. Fondo de Cultura Económica.

Wittgenstein, L. (2010). Investigaciones filosóficas. Instituto de Investigaciones Filosóficas. 